\title{
INCLUSÃO SOCIAL NO ÂMBITO TRANSNACIONAL
}

\author{
Lincoln Simões Fontenele \\ Aluno do Curso de Direito da FA7. Relato sob a orientação \\ do prof. Me. Ramon Negócio (FA7). \\ lincoln.simoes@hotmail.com
}

\section{INTRODUÇÃO}

A partir dos estudos realizados no grupo de estudo Direito e Globalização da Fa7, novas perspectivas jurídicas e sociais surgiram e impulsionaram a pesquisa aqui relatada sobre a questão da inclusão de indivíduos nas demais esferas sociais. Assim, este relato de pesquisa acompanha as consequências da globalização na sociedade, faz contraponto de dois aportes teóricos sobre a legitimidade do direito em Luhmann e em Habermas e propõe o transconstitucionalismo de Marcelo Neves para buscar entender como é possível ocorrer, deixando de lado utopias irrealizáveis, a inclusão de indivíduos por meio da esfera jurídica nos diversos subsistemas sociais inseridos no âmbito de uma sociedade mundial, que é fragmentada e com pouca expressão política no campo transnacional.

Para isso, faz-se necessário, a partir da metodologia utilizada, qual seja, a pesquisa teórica, explicar alguns pressupostos teóricos da teoria dos sistemas de Luhmann, tendo em vista sua pouca divulgação no Brasil, e suas particularidades no que se refere aos termos de estudo da sociedade e do direito. A partir disso, discutir-se-á a questão da legitimidade advinda pelo próprio direito ou pelo discurso democrático, as consequências da globalização na sociedade e a questão de como se pode incluir os indivíduos nas demais esferas sociais com a participação do direito.

\section{Teoria dos Sistemas e Direito}

Niklas Luhmann recebeu influência de Talcott Parsons e de sua Teoria dos Sistemas, a qual concebe a sociedade como um sistema dividido em subsistemas que têm como elemento a comunicação. A partir disso, aprofundou-se no tema e orientou-se no sentido de construir uma grande teoria capaz de explicar a sociedade e a vasta gama de fenômenos sociais em seu meio (LUHMANN, 2005, p. 23). Com tal teoria configurando a sociedade moderna como um sistema composto por comunicação, contribuiu-se para uma inovação na sociologia que veio afirmando, há muito tempo, que a sociedade é composta por indivíduos.

Tendo isso em mente, frente ao grau de complexidade das comunicações, a sociedade moderna é fragmentada em "subsistemas funcionais que reproduzem comunicações submetidas 
mais restritivas, balizadas pelos códigos binários específicos de cada subsistema" (VILLAS BÔAS FILHO, 2009, p. 93). Por exemplo, o direito tem o código lícito/ilícito, a economia ter/não-ter, política poder/não-poder, etc., e cada informação é observada a partir desse ponto de vista binário. Assim, quando o direito observa algo, ele só responde se é lícito ou ilícito.

Cada subsistema desses tem uma função, a qual, para Luhmann, não é um efeito a ser alcançado, como afirmava Parsons, mas sim "um esquema regulador de sentido, que organiza um âmbito de comparação de efeitos equivalente" (LUHMANN, 2005, p. 29). Ou seja, a função do sistema ou subsistema é reduzir a relação de complexidade entre si e seu ambiente, uma vez que é em atendimento a essa demanda que eles surgem.

O direito, subsistema funcional, estabiliza as expectativas nas interações definindo seus limites. Para isso, ele aplica seu código binário lícito/ilícito de modo que reduza a contingência do ambiente. Assim, permite-se que cada indivíduo espere algo do outro com o mínimo de garantia (LUHMANN, 1980, p. 1). É exatamente por ter esse código binário próprio que ele se individualiza com relação aos outros subsistemas. Eis a sua identidade, a qual tem um conteúdo que, se preenchido, ensejará em uma resposta do direito. Esse programa condicional é composto por formulações das condições para que as decisões dos juízes ou tribunais, ao aplicar o direito, apliquem-no juridicamente correto (LUHMANN, 1985, p. 27). Ou seja, "se forem preenchidas determinadas condições [...], deve-se adotar determinadas decisões” (p. 28).

Quanto ao aplicador dessas decisões, tem-se que ele segue os limites de seu papel para atuar e o programa estabelecidos pelo próprio direito. Quer dizer, aquele que se encontra na situação de tomar decisões jurídicas está incorporado no papel de Juiz/Tribunal e, desse modo, limitado à aplicação do código binário em conformidade com o programa jurídico existente. Observa-se, então, que a atuação do direito conforme seus próprios elementos mostra que ele é autoreferencial e autônomo, sem deixar-se determinar pelos outros subsistemas (Cf. NEVES, 2006, p. 79 ss.), sendo essencial para a especificação de sua função e para assegurar "sua própria unidade operativa" (VILLAS BÔAS FILHO, 2009, p. 145). Ou seja, o direito tem uma clausura operativa que lhe permite trabalhar segundo suas próprias estruturas, o que não quer dizer que ele se isola do ambiente, pois, quanto a este, o direito é cognitivamente aberto. Desse modo, por meio de irritações de seu ambiente, ele se autorreproduz com os seus próprios recursos. Daí a adjetivação de autopoiético emprestada da biologia.

\subsection{Legitimidade do Direito}

$\mathrm{O}$ direito precisa de algo que dê às suas decisões efeitos vinculativos. Ou seja, todos precisam aceitar a validade da decisão aplicada. O fator de justificação do direito é, portanto, a sua legitimidade.

Torna-se pertinente, assim, saber como essa legitimidade é gerada e quais os mecanismos de tal feito na sociedade moderna. Ora, duas teorias divergem radicalmente quando se trata de legitimidade do direito: a Teoria do Discurso, de Habermas, e a Teoria dos Sistemas, de Luhmann.

Habermas aponta que o direito em um Estado Democrático de Direito deve ser legítimo para ele ser direito e para que ele aja como tal. Frente a isso, sua teoria vai ter o procedimento democrático como fator de legitimação do direito (HABERMAS, 1997, p. 191), pois aqueles que se submeterão às normas estarão se submetendo a si mesmos. Para ele, nada mais razoável. O indivíduo que receber a decisão de um juiz deve aceitá-la de bom grado, porque ele está se submetendo a uma norma que ele mesmo construiu democraticamente junto 
de seus pares. Portando, “a validade de qualquer tipo de norma de ação está submetida ao assentimento daqueles que, na qualidade de atingidos, tomam parte em 'discursos racionais"” que a produziram (p. 199).

Quanto a Luhmann, a legitimidade é questão de crença (FERRAZ JUNIOR, 2003, p. 350). Ou seja, para que uma norma seja legítima, é preciso que ela seja acreditada como legítima. Diz ele que o direito é legítimo quando há "uma disposição generalizada para aceitar decisões de conteúdo ainda não definido dentro de certos limites de tolerância" (LUHMANN, 1980, p. 30). Até aqui, não difere muito de Habermas. No entanto, a distância de suas teorias nessa questão se situa em como se produz essa crença na legitimidade.

Já Habermas aponta que o que legitima o direito é procedimento democrático (Cf. HABERMAS, 1997, p. 174), isto é, algo externo a ele. Luhmann diverge radicalmente quando diz que há mecanismos internos do direito que geram sua legitimação. Ou seja, o direito conta com seus próprios mecanismos para gerar aceitação e, por conseguinte, legitimidade, que independe quase inteiramente do conteúdo das normas, o que é lógico de se concluir, visto que, na teoria dos sistemas, o direito é um subsistema autorreferencial e autopoiético, como explicado anteriormente.

Os mecanismos do direito para isso são: processos e força simbólica (LUHMANN, 1985, p. 64). Por enquanto, seus modos de operação no sentido de gerar aceitação serão objeto de pesquisa mais aprofundada no futuro. Para este relato, basta o que foi dito.

\section{Ordens Transnacionais}

Diante do fenômeno da globalização, a dinâmica das comunicações sociais ultrapassou bastante os limites territoriais dos Estados. Assim, pesquisar neste âmbito significa estudar uma sociedade mundial que se diferencia em subsistemas funcionais que atuam em uma esfera transnacional.

Trans significa algo que vai "além de". Desse modo, transnacional é algo que vai além da nação. Em razão disso, e para começar o argumento proposto, conclui-se que o subsistema político se encontra bastante atrasado por estar restrito ao território onde tem poder legítimo. Resta, portanto, declarar que o que se experimenta "não é uma globalização unitária da sociedade sob a condução da política, e sim processos globalizadores fragmentados da sociedade civil em relativa independência da política" (TEUBNER, 2003, p. 12). Ou seja, os demais subsistemas funcionais da sociedade participam do processo de globalização com velocidades diferentes sem participação efetiva da política.

É comum que tais subsistemas se relacionem entre si. Assim, tais relações em âmbito transnacional são uma abertura para a destruição de um sistema pelo outro se não houver algo que os regule (HOLMES, 2011, p. 115-116). Por exemplo, a relação entre a economia e a ciência deve ser regulada para que não ocorra uma corrupção em razão da economia determinar a ciência. Isso que dizer que certo resultado científico pode ser determinado pelo dinheiro, e não pela pesquisa que dirá se ele é verdadeiro ou falso.

Frente a isso, há uma demanda por parte desses subsistemas por uma estabilização de suas expectativas realizada por um direito que, necessariamente, irá além do Estado-nação, pois neste há apenas jurisdição com atuação restringida pela política. 
Com a resumida política em âmbito transnacional, o direito público não conseguirá suprir as demandas dos subsistemas transnacionais, que são setores sociais, como a economia, a ciência, a mídia, o turismo, a cultura (TEUBNER, 2003, p. 13). Por conseguinte, o direito privado, que é construído pela sociedade civil, emergirá como um direito transnacional, visto que perpassa limites territoriais, a partir das zonas de contatos com outros subsistemas sociais, e não no centro de Estados-nações (p. 14). Ou seja, as relações, que demandam de estabilização de expectativas, criarão o seu próprio direito que terá a função de estabilizar suas expectativas.

Pela existência de ordens públicas e privadas, pode-se falar em direito global, ou mundial. Essas suas ordens privadas surgem de modo fragmentado, pois é produzido para relações específicas. Isso quer dizer que há vários regimes privados de direito regulando as relações transnacionais. Tais regimes seguem as mesmas estruturas, mas apenas com conteúdos diferentes para a aplicação do seu código lícito/ilícito, isto é, tem programas variados conforme seja a necessidade dos particulares em relações específicas.

Um caso de sucesso dessa realidade é a chamada lex mercatoria. Ela, conjunto de regimes privados de direito transnacional ligado à economia, tem seus regimes compostos pelos contratos que representam relações entre o setor econômico transnacional e outro setor social, que pode ser transnacional ou não. Seu triunfo se dá com a aplicação do próprio contrato em detrimento da aplicação de ordens estatais em tribunais arbitrais (MENDES, 2010, p. 37). Isso ocorre principalmente porque a "lex mercatoria tem se mostrado mais conveniente em casos nos quais é extremamente difícil determinar o direito aplicável de acordo com as regras tradicionais de Direito Internacional Privado" (p. 32).

Tais regimes privados não geram apenas respostas para os casos transnacionais. Geram também conflitos, que "não são entre o direito interno das nações, mas das colisões entre distintos setores globais" (TEUBNER e FISCHER-LESCANO, 2004, p. 1000). Já era de se esperar tal situação diante de uma pluralidade de regimes na sociedade mundial. São possíveis, então, colisões entre regimes privados e públicos. Afinal, é inevitável, frente à crescente dinâmica transnacional das comunicações, uma "fragmentação legal da sociedade global que não pode, por si só, ser combatida" (p. 1004).

\section{Direito Como InClusão}

Na semântica das revoluções burguesas, cidadão era aquele que tinha direitos políticos. Hoje, essa concepção está mais estendida e atinge um grau no qual o cidadão é aquele que tem direitos sociais, o que inclui direitos políticos, econômicos, culturais, tecnológicos (NEVES, 1994, p. 254). Isso quer dizer que ele se encontra incluído nos diversos subsistemas sociais da sociedade, pois o direito consegue garantir, ao regular as comunicações e, assim, manter estáveis as expectativas que os indivíduos inseridos nos mais variados papéis têm dos outros indivíduos. Por conseguinte, esse indivíduo incluído tem acesso aos benefícios dos sistemas funcionais (p. 292). Como já foi dito antes, o direito regulará a sociedade de modo que nenhum subsistema possa engolir o outro e, desse modo, dominá-lo ou excluí-lo.

Para concluir o conceito nos dizeres de Marcelo Neves: “[...] a cidadania, enquanto integração generalizada nos sistemas sociais, com base no Direito, amplia-se significativamente com a conquista dos direitos sociais [...]" (NEVES, 1994, p. 257).

Agora, a questão que fica aberta é a cidadania no âmbito transnacional. Não se fala mais em buscar um cidadão no Estado-nação, mas sim um cidadão do mundo. 


\section{Considerações Finais}

Frente à situação global descrita, a simples atuação do direito no âmbito transnacional com força vinculante implica concluir que sua legitimação realmente é interna e, por isso, gera problemas quando regimes de direito autolegitimados se chocam com outros regimes de direito heterárquicos e, também, autolegitimados, tendo, ambos, força vinculante.

Tal direito transnacional, como descrito, é construído pela sociedade civil para determinadas situações específicas. Justamente por ser um direito privado, ele terá seu conteúdo programático dependente das partes. Portanto, a inclusão social, também conforme descrita, torna-se problemática neste âmbito transnacional, tanto por falta de política quanto por atuação de atores privados.

Frente a essa situação, o transconstitucionalismo, proposto por Marcelo Neves, pode ajudar na questão da inclusão, pois "serve como um modelo estrutural de conexão funcional entre as esferas funcionais fragmentadas da sociedade mundial" (NEVES, 2009, p. 288). Essa conexão serve para estruturar as ordens jurídicas aqui demonstradas, os regimes de direito, com o oferecimento de "pontes de transição" entre elas, fazendo com que haja condições de "tecelagem" dos fragmentos (p. 288-289).

O transconstitucionalismo oferece, basicamente, um diálogo entre ordens, que devem ser cognitivamente abertas para terem uma adaptação social. Possibilita-se, desse modo, a realização da inclusão social no âmbito transnacional.

\section{REFERÊNCIAS}

FERRAZ Junior, Tercio Sampaio. Introdução ao estudo do direito: técnica, decisão, dominação. São Paulo: Atlas, 2003.

HABERMAS, Jürgen. Direito e democracia: entre faticidade e validade. Vol. I. Rio de Janeiro: Tempo Brasileiro, 1997.

HOLMES, Pablo. The rhetoric of 'legal fragmentation' and its discontents: evolutionary dilemmas in the constitutional semantics of global law. Utrech Law Review, 2011: 113-140.

LUHMANN, Niklas. EI derecho de la sociedad. Herder, 2005.

. Legitimação pelo procedimento. Brasília: Editora Universidade de Brasília, 1980.

. Sociologia do Direito II. Rio de Janeiro: Tempo Brasileiro, 1985.

MENDES, Rodrigo Octávio Broglia. Arbitragem, Lex Mercatoria e Direito Estatal: uma análise dos conflitos ortogonais no Direito Transnacional. São Paulo: Quartier Latin, 2010.

NEVES, Marcelo. Entre Subintegração e Sobreintegração: a cidadania inexistente. Revista de Ciências Sociais 37 (1994). 253-276.

. Entre Têmis e Leviatã: uma relação difícil: o Estado Democrático de Direito a partir e além de Luhmann e Habermas. São Paulo: Martins Fontes, 2006.

. Transconstitucionalismo. São Paulo: Martins Fontes, 2009. 
TEUBNER, Gunther. A bukowina global sobre a emergência de um pluralismo jurídico transnacional. Impulso, 2003, p. 9-31.

TEUBNER, Gunther e FISCHER-LESCANO, Andreas. Regime-Collisions: the vain search for legal unity in the fragmentation of global law. Michigan Journal of International Law 25 (2004), p. 999-1046.

VILLAS BÔAS FILHO, Orlando. Teoria dos sistemas e o direito brasileiro. São Paulo: Saraiva, 2009. 